\title{
Atypical porcine pestivirus in piglets with congenital tremor in central China
}

Zhi $\mathrm{Cao}^{1}$, Ying $\mathrm{Yu}^{2}$, Shuai $\mathrm{Ma}^{2}$, Shilei Zheng ${ }^{2}$, and Heng Zhang ${ }^{2}$

${ }^{1}$ Chinese Academy of Fishery Science Yellow Sea Fisheries Research Institute

${ }^{2}$ Affiliation not available

June 1,2020

\section{Abstract}

This study is the first to demonstrate an atypical porcine pestivirus (APPV) HeN01 strain isolated from congenital tremor (CT) diseased piglets in Henan, Central China, indicating that APPV has spread north of the Yangtze River. The epidemiological monitoring of APPV and the health management of livestock in northern China should be increased to prevent outbreaks and animal loss. In addition, we successfully isolated APPV to provide a material basis for the development of APPV vaccines.

\section{Hosted file}

manuscript.doc available at https://authorea.com/users/328670/articles/455829-atypicalporcine-pestivirus-in-piglets-with-congenital-tremor-in-central-china
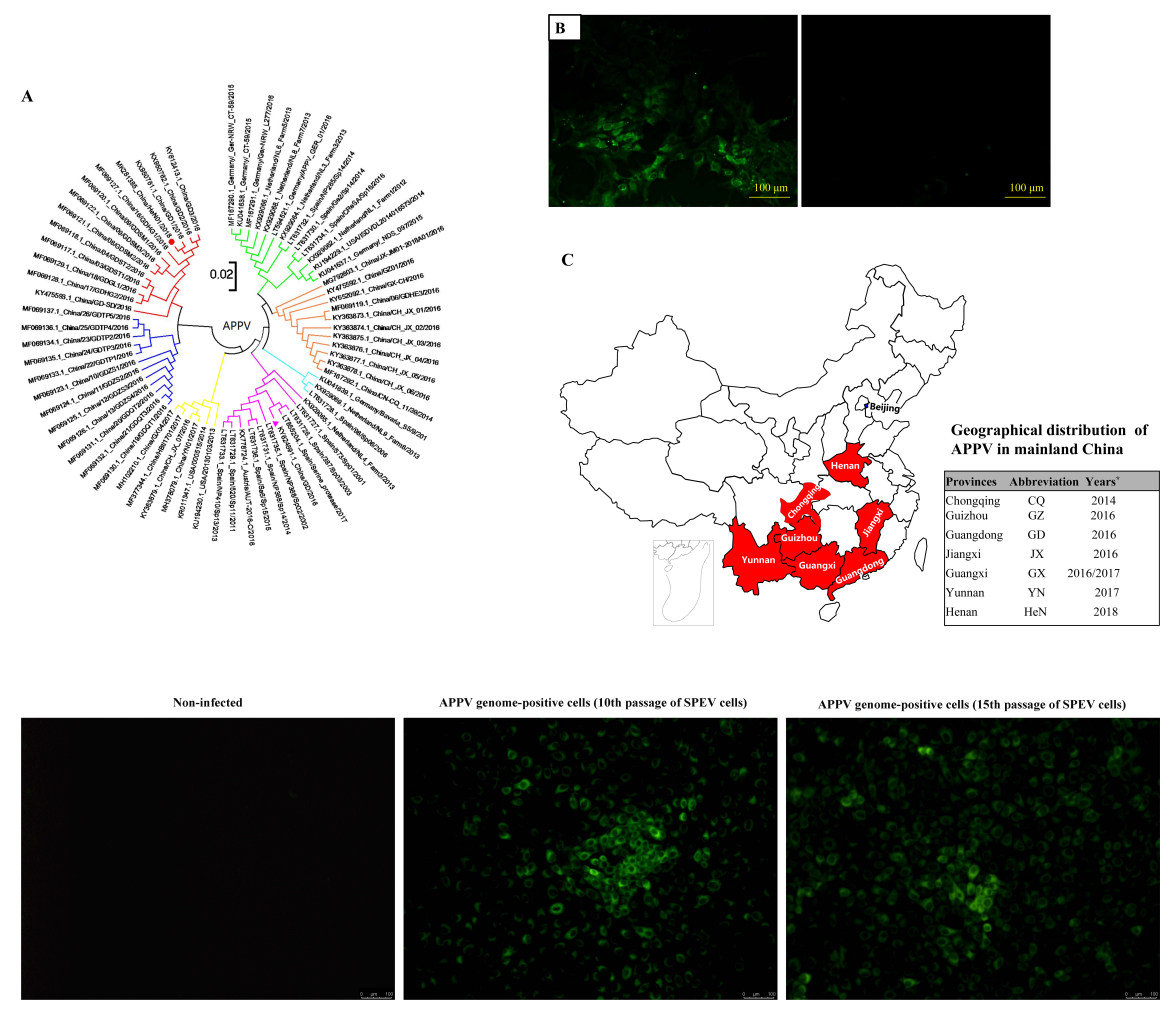